\title{
Dinâmica dos precursores celulares do epitélio olfatório de cães sem raça definida: um estudo imunohistoquímico e ultra-estrutural ${ }^{1}$
}

\author{
Flávio Ribeiro Alves ${ }^{2 *}$, Tatiana Carlesso Santos ${ }^{3}$, Sandra Freiberger ${ }^{3}$, Carlos Eduardo \\ Ambrósio $^{3}$ e Maria Angélica Miglino ${ }^{3}$
}

\begin{abstract}
Alves F.R., Santos T.C., Freiberger S., Ambrósio C.E. \& Miglino M.A. 2007. [The dynamic of precursor of the olfactory epithelium of mongrel dogs: an immunohistochemical and ultrastructural study.] Dinâmica dos precursores celulares do epitélio olfatório de cães sem raça definida: um estudo imunohistoquímico e ultra-estrutural. Pesquisa Veterinária Brasileira 27(9): 388-392. Departamento de Cirurgia, Faculdade de Medicina Veterinária e Zootecnia, USP, Av. Prof. Dr. Orlando Marques de Paiva 87, São Paulo, SP 05508-270, Brazil. E-mail: flaviovet@usp.br

Olfactory epithelium presents a mechanism of differentiation where stem cells give arise to amplifying progenitor cell which express Mammalian Achaete Scute Homolog 1 (Mash1). These cells can be differentiated into olfactory receptors. An immunolocalization study and ultrastructural analysis by transmission electron microscopy of olfactory epithelium of mongrel dogs were made using 3 males (one year old) and 2 females (three years old). Labeled cells with positive staining by Proliferating cell nuclear antigen (PCNA) were observed in specific areas of the olfactory epithelium, especially above the basal membrane. The ultrastructure revealed cells adjacent to the basal membrane with morphology resembling sustentacular cells, supporting the idea of renewal of sustentacular and olfactory sensorial cells. Olfactory epithelium contains basal cells committed to self-renewal, characterized by high metabolic activity, identified by positive reaction to PCNA. These results suggested the renewal of sustentacular and sensorial olfactory cells through the same pathway.
\end{abstract}

INDEX TERMS: Olfactory epithelium, basal cells, precursor cells, PCNA method.

RESUMO.- O epitélio olfatório apresenta um mecanismo de diferenciação em que células-tronco dão origem a células progenitoras amplificadoras, as quais expressam um gene próneural denominado Mammalian Achaete Scute Homolog 1 (Mash1). Estas células podem se diferenciar em receptores olfatórios. $O$ epitélio olfatório de cães sem raça definida (3 machos de um ano e 2 fêmeas de três de idade) foi analisado por imunolocalização do antígeno nuclear de proliferação celular (PCNA) e por microscopia eletrônica de transmissão. Verificou-se marcação positiva para PCNA em células do epitélio olfatório, particularmente acima da linha da mem-

\footnotetext{
${ }^{1}$ Recebido em 16 de maio de 2007.

Aceito para publicação em 18 de setembro de 2007.

2 Pós-Graduando em Anatomia dos Animais Domésticos e Silvestres, Departamento de Cirurgia, Faculdade de Medicina Veterinária e Zootecnia (FMVZ), Universidade de São Paulo (USP), Av. Prof. Dr. Orlando Marques de Paiva 87, Cidade Universitária, São Paulo, SP 05508-270, Brasil. *Autor para correspondência: flaviovet@usp.br

${ }^{3}$ Departamento de Cirurgia, FMVZ, USP, São Paulo, SP.
}

brana basal. A ultra-estrutura do epitélio olfatório revelou células adjacentes à lâmina basal, cuja eletrodensidade assemelha-se àquelas presentes no epitélio de sustentação, reforçando a idéia da renovação das células de sustentação e dos neurônios olfatórios locais. $O$ epitélio olfatório é composto células basais, comprometidas com sua renovação, caracterizadas através da intensa atividade mitótica, identificada pela reação positiva ao PCNA. Estes resultados sugerem que há reposição das células sustentaculares locais e do sistema através de mecanismos semelhantes.

TERMOS DE INDEXAÇÃO: Epitélio olfatório, células basais, células precursoras, método PCNA.

\section{INTRODUÇÃO}

Muitos mamíferos terrestres apresentam em suas cavidades nasais receptores ou elementos especializados do sistema neural (Graziadei \& Graziadei 1979). Em humanos, os receptores sensoriais olfatórios encontram-se localizados no recesso superior da cavidade nasal, dentro de um neuroepitélio 
que envolve a lâmina cribforme, parte superior e média do osso etmóide e septo nasal (Huard et al. 1998). Em anfíbios, o neuroepitélio é fino e plano, enquanto em roedores, carnívoros e outros mamíferos, encontra-se distribuído sobre uma superfície caracterizada por um complexo de pregas turbinadas, que se originam do osso etmóide (Carr et al. 1991).

O epitélio olfatório de ratos é composto por seis tipos celulares característicos: neurônios bipolares, células sustentaculares, células microvilares localizadas na superfície do epitélio, células que envolvem os ductos e glândulas olfatórias, e as células globosas e horizontais basais, localizadas no compartimento basal no qual muitos outros tipos celulares são originados (Menco \& Jackson 1997). Em seus estudos em camundongos, quando avaliaram o tempo de imunomarcação do epitélio olfatório, Mackay-Sim \& Kittel (1990) e Hind et al. (1984) descreveram essas células exercendo um papel fundamental para o entendimento dos mecanismos de degeneração e regeneração dentro do neuroepitélio olfatório.

Para Calof et al. (2002) existe um mecanismo de diferenciação em que células-tronco dão origem a células progenitoras amplificadoras, que por sua vez expressam um gene pró-neural denominado Mammalian Achaete Scute Homolog 1 (Mash1). Este dá origem a um segundo progenitor amplificador transitório, o precursor neuronal imediato (INP), que pode ser distinguido pela expressão do gene proneural neurogenina 1 (Ngn1). O precursor neuronal imediato divide-se para dar origem a duas células irmãs, as quais por fim se diferenciam em receptores olfatórios de neurônios.

Nesse contexto, a possibilidade de promover diferenciação celular através de uma célula pluripotente motivou estudos que tem evidenciado receptores de neurônios olfatórios, produzidos a partir de uma linhagem que apresenta tipos celulares de proliferação distinta. Como existem ainda muitas controvérsias com relação ao processo de diferenciação celular do neuroepitélio olfatório, busca-se, no estudo dessas células, contribuir para elucidar as dúvidas ainda existentes sobre os mecanismos de produção e regeneração dessas células. Sendo assim, o presente trabalho objetiva descrever, em cães sem raça definida, a dinâmica dos precursores celulares do epitélio olfatório.

\section{MATERIAL E MÉTODOS}

Foram utilizados cinco cães sem raça definida, pesando em média $20 \mathrm{~kg}$, sendo três machos de um ano de idade e duas fêmeas de três anos. Os cães foram provenientes do Hospital Veterinário da Faculdade de Medicina Veterinária e Zootecnia da Universidade de São Paulo (USP), depois de constatada morte por causas naturais ou alterações patológicas.

\section{Imunohistoquímica}

Fragmentos da superfície da lâmina crivosa do etmóide, da cavidade nasal dos cães, foram obtidos e fixados em Metacarn (60\% metanol, $30 \%$ clorofórmio e $10 \%$ de ácido acético glacial) por 24 horas ou em glutaraldeído 2,5\%, tampão fosfato $0,12 \mathrm{M} \mathrm{pH} \mathrm{7,3.} \mathrm{Após} \mathrm{a}$ fixação, o material coletado foi processado na rotina histológica para ser emblocado em paraplast e seccionado em cortes de $5 \mathrm{~mm}$, montados em lâminas silanizadas. Estes cortes foram submetidos a imunohistoquímica para determinação do antígeno nuclear de proliferação celular (PCNA), com o objetivo de identificar as células em proliferação.

Os cortes histológicos foram desparafinados e desidratados em séries decrescentes de etanol e em seguida foram bloqueados, durante 5 minutos, em solução de peróxido de hidrogênio a $3 \%$ e lavados abundantemente em PBS. A seguir, os cortes foram incubados, durante 15 minutos, à $37^{\circ} \mathrm{C}$ em uma solução de leite desnatado a $5 \%$. Após essa etapa, os cortes sofreram 3 lavagens de 5 minutos em PBS. Prosseguiu-se então a incubação com anticorpo monoclonal PCNA (Zymed, Cat. 13-3900), na concentração de 1:100, overnight em câmara úmida. Em seguida, após 3 lavagens de 5 minutos com PBS, as lâminas foram incubadas com anticorpo biotinilado de cabra anticamundongo (Kit LSAB-Dako, Cat. EO433), por 1 hora. Depois, os cortes foram tratados com o complexo estreptavidina-peroxidase (Kit LSAB-Dako, Cat. EO433), por 30 minutos. Após lavagens sucessivas com PBS, os cortes foram incubados com a diaminobenzidina, juntamente com peróxido de hidrogênio, durante 10 minutos.

As lâminas foram então coradas pela hematoxilina e montadas com o Bálsamo do Canadá. Os cortes foram analisados em um microscópio Nikon E800 e as imagens obtidas no programa Image Proplus.

\section{Microscopia eletrônica de transmissão (MET)}

Os fragmentos da mucosa nasal da região da lâmina crivosa do etmóide também foram fixados em glutaraldeído 2,5\% (tampão fosfato $\mathrm{pH} 7,3 ; 0,1 \mathrm{M})$. Os fragmentos foram então lavados em três passagens de 10 minutos em tampão fosfatos $0,1 \mathrm{M}$, pós-fixados em tetróxido de ósmio, e lavados a seguir em três passagens de 10 minutos em água destilada. Posteriormente adicionou-se uranila sob agitação por uma hora em câmara escura. $\mathrm{O}$ material foi então desidratado em séries crescentes de etanol, seguido por óxido de propileno e embebido em resina de araldite. A resina de inclusão foi submetida a vácuo por 30 minutos. Após a secagem procedeu-se à confecção das telas para leitura em um microscópio eletrônico de transmissão (Philips Morgagni 268 D).

\section{RESULTADOS E DISCUSSÃO}

Análise da imunohistoquímica e da MET do epitélio olfatório de cães sem raça definida sugerem que nesta espécie ocorra proliferação celular a partir de células basais, as quais provavelmente sejam as fontes para a renovação celular desde epitélio.

$O$ estudo imunohistoquímico foi realizado utilizando técnica para marcação do antígeno de proliferação celular (PCNA) que possibilitou a observação desse mecanismo para as células do epitélio olfatório, corroborando com as citações de Tsuji et al. (1992) e Pendleton et al. (1993) em humanos, para os quais a técnica de imunohistoquímica lança mão de marcadores de proteínas expressas em sua maior parte no ciclo celular. Embora autores como Legrier et al. (2001) tenham demonstrado através de marcações positivas para BrdU e PCNA em células do epitélio olfatório de camundongos, que o mecanismo de proliferação celular pode diminuir de 10 a 15 vezes desde o nascimento até os três primeiros meses de idade, ao realizarmos um estudo cego da marcação através de PCNA do epitélio olfatório de cães adultos, não foi verificada diferença quantitativa de marcação entre os indivíduos dos dois grupos etários estudados, ou entre os sexos. Resultados que corroboram os encontrados por Roisen et al. 

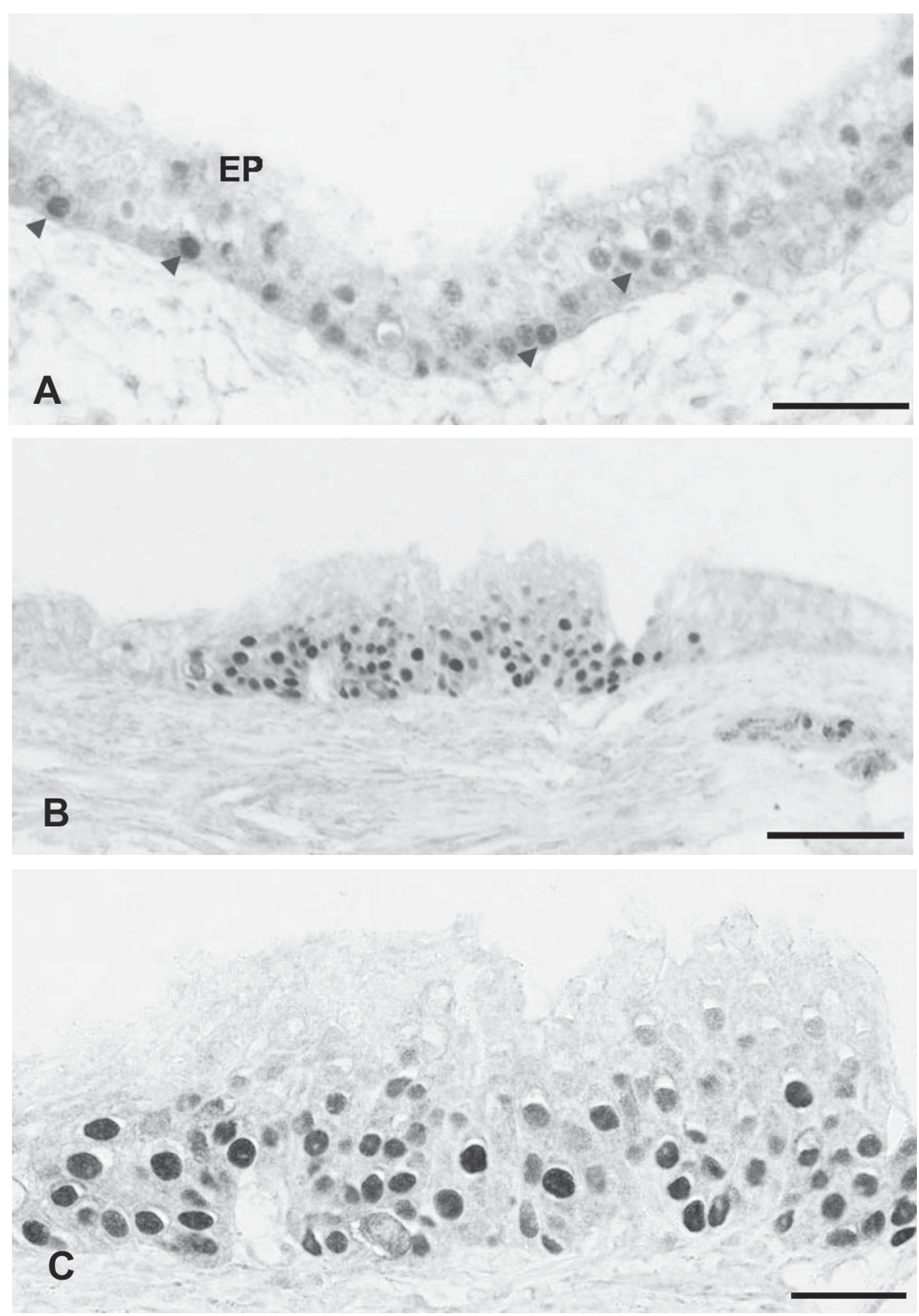

Fig.1. a) Fotomicrografia de corte da mucosa nasal de cão, caracterizando marcação positiva para PNCA (setas). Marcação variada e dispersa em vários pontos do epitélio (setas). b) Característica da marcação por PNCA disposta de forma estratificada no epitélio da mucosa olfatória. c) Maior aumento da região marcada em (b). Barras = a) $25 \mu \mathrm{m}$, b) $50 \mu \mathrm{m}$, c) $40 \mu \mathrm{m}$.

(2001), quando estudou o epitélio olfatório através de biópsias em humanos de diferentes sexos e idades.

A marcação do epitélio olfatório através da técnica de imunohistoquímica ocorreu de forma variada, sendo verificada com maior ou menor intensidade, na dependência da região observada (Fig.1a). A característica pseudoestratificada deste epitélio também possibilitou a observação de núcleos de células marcados positivamente, em diversas camadas celulares (Fig.1b,1c). Essa observação encontrou-se alicerçada nas hipóteses da localização das sub-populações de células-tronco residentes nas porções média e basal do epitélio olfatório, como também foi descrito por Nakamura et al. (1998) e Higuchi 


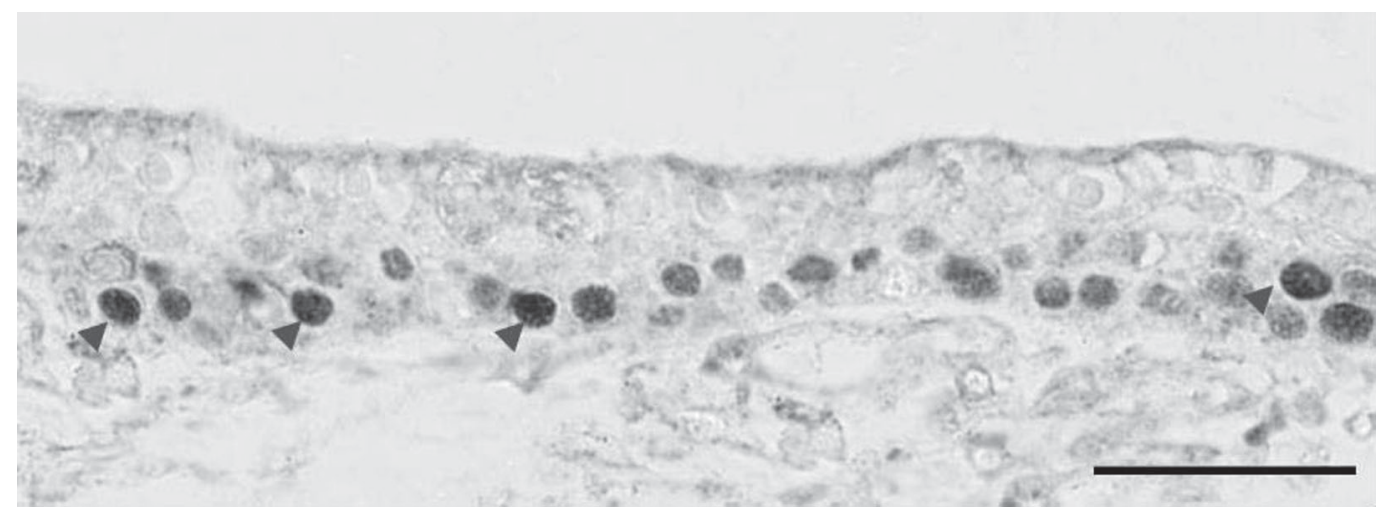

Fig.2. Intensa atividade de proliferação celular basal (setas), local provável de diferenciação e localização das células progenitoras de renovação das estruturas componentes deste epitélio. Barras $=40 \mu \mathrm{m}$.
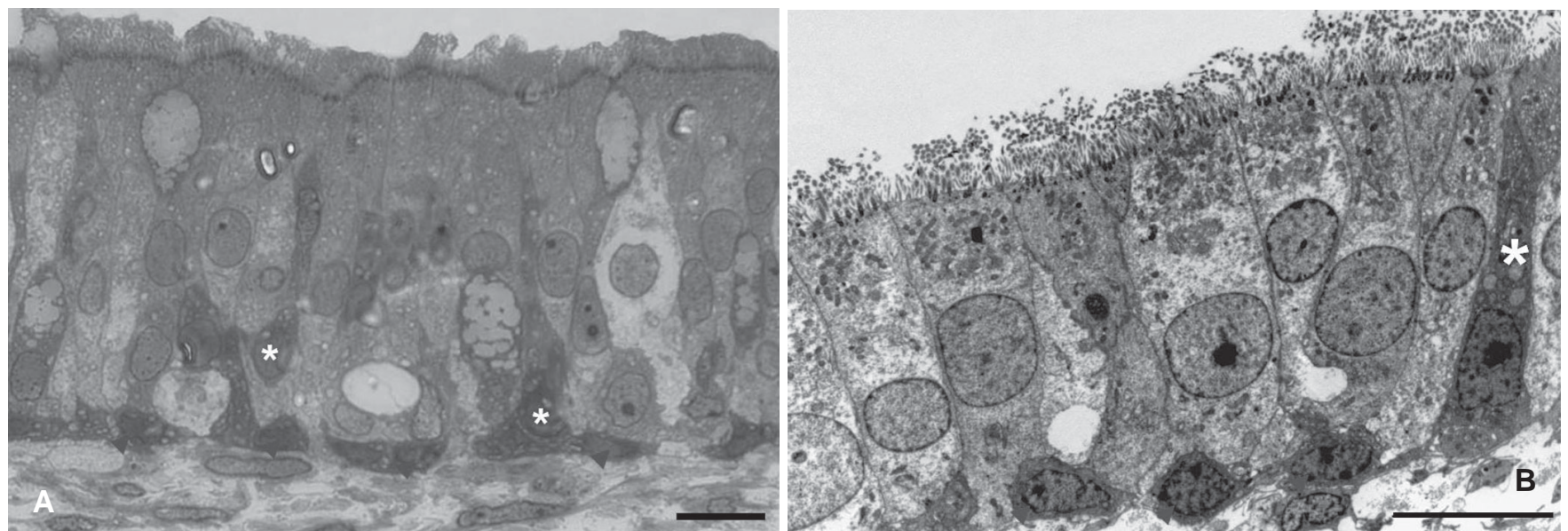

Fig.3. a) Corte semi-fino de epitélio olfatório de cão em que se observam células com núcleos mais intensamente corados pelo Azul de Toluidina adjacentes a lâmina basal (setas) e em células colunares (*). b) Eletromicrografia demonstrando células progenitoras (setas) presentes na lâmina basal, sugerindo a renovação do epitélio, apresentando núcleos com morfologia semelhante a de algumas células colunares eletrodensas (*). Barra = a) $10 \mu \mathrm{m}$, b) $10 \mu \mathrm{m}$.

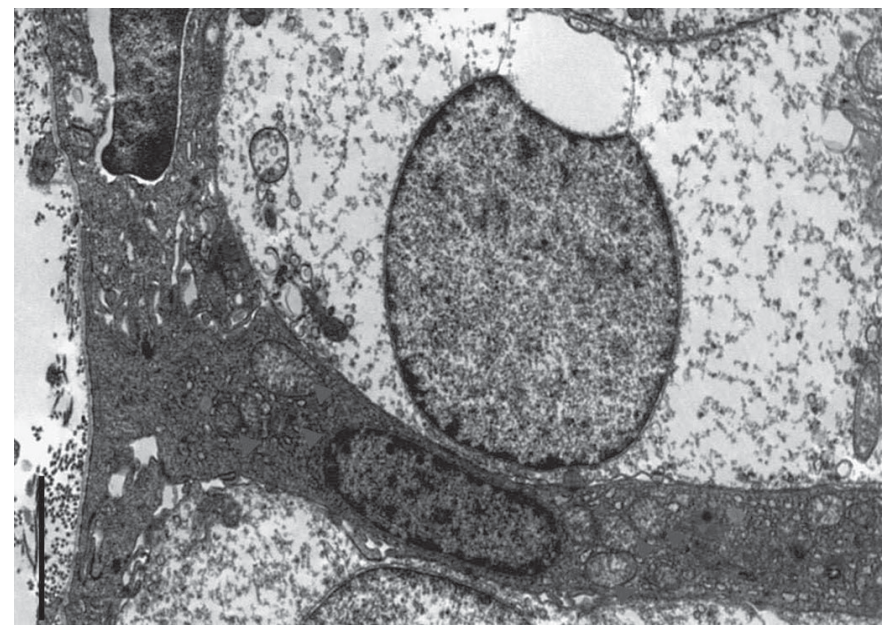

Fig.4. Eletromicrografia do epitélio olfatório de cão, demonstrando a atividade metabólica entre as células basais e colunares, caracterizada pelas mitocôndrias dispersas pelo citoplasma dessas células (setas), bem como pelo nível de condensação da cromatina nuclear. Barra $=2 \mu \mathrm{m}$. et al. (2005), em estudos da dinâmica dos precursores celulares do epitélio olfatório em Cavia sp. jovens. Tais resultados também foram compartilhados por Ohta \& Ichimura (2000), quando estes estudaram alterações da proliferação celular e a presença do fator de crescimento epidermal (EGFR) no epitélio olfatório de ratos através de técnica de imunohistoquímica para identificação de PCNA. Corroboram ainda a estes achados Legrier et al. (2001) em seus estudos sobre o ciclo de regulação da neurogênese em ratos.

Verificou-se uma preferência por núcleos de células mais próximos a membrana basal (Fig.2), onde se visualizou alta taxa de atividade de proliferação celular. Tais características foram condizentes com as observações feitas por Levey et al. (1991) e Getchell et al. (2000) ao retratarem o mecanismo de diferenciação basal de células do epitélio olfatório em ratos, através de técnica de imunohistoquímica, com marcação positiva para citoqueratinas, identificando preferencialmente células horizontais basais (HBC's). Estas células foram descritas povoando uma região paralela e em contato com a lâmina própria nesses ratos.

No material analisado não foram identificados núcleos de 
células em atividade mitogênica imunomarcados para PCNA no tecido conjuntivo, achado este compartilhado também por Holcomb et al. (1995), Huard et al. (1998), Kovacs et al. (1999), Legrier et al. (2001), Jin et al. (2002) e Kawauchi et al. (2004), em seus estudos realizados em camundongos. No epitélio de cães sem raça definida, a manifestação do potencial mitogênico das células sugeriu predileção por determinadas áreas do epitélio, onde a marcação do PCNA no núcleo foi vista mais intensamente.

A análise dos corte semi-finos demonstrou que as células positivas para PCNA correspondem a um grupamento celular típico em região adjacente à lâmina basal (Fig.3). À análise ultra-estrutural as células basais caracterizaram-se por estar em contato com a membrana basal, apresentando citoplasma eletrodenso, com núcleos esféricos e presença de eucromatina, ocupando grande parte da célula. Células com eletrodensidade semelhante às células basais foram encontradas dispersas por entre as células de sustentação. A morfologia dessas células sugere um estágio intermediário entre as células basais e as sustentaculares (Fig.3), reforçando a idéia da renovação do epitélio, das células de sustentação e dos demais componentes olfatórios locais. Esses achados são condizentes com as citações feitas por Caggiano et al. (1994), Huard et al. (1998), Nakamura et al. (1998) e Higuchi et al. (2005), sustentando a hipótese da presença de células progenitoras residentes entre as células basais do epitélio olfatório, dando origem a todos os constituintes desta região, particularmente neurônios olfatórios.

Entre as células basais e colunares, verificou-se intensa atividade metabólica, caracterizada pela presença de mitocôndrias e pelo grau de condensação da cromatina nuclear (Fig.4), conforme foi descrito por Roisen et al. (2001) em estudo ultraestrutural e de cultura de células-tronco do epitélio olfatório de indivíduos adultos humanos.

\section{CONCLUSÃO}

O epitélio olfatório apresenta uma linhagem de células localizadas em sua camada basal, comprometidas com a renovação celular nessa região, caracterizada pela atividade mitótica identificada pela reação positiva ao PCNA presente em seus núcleos, sugerindo que a reposição das células sustentaculares e dos neurônios olfatórios locais olfatórios locais podem ser realizadas através de mecanismos de renovação semelhantes.

\section{REFERÊNCIAS}

Caggiano M., Kauer J.S. \& Hunter D.D. 1994. Globose basal cells are neuronal progenitors in the olfactory epithelium: a lineage analysis using a replication-incompetent retrovirus. Neuron. 13:339-352.

Calof A.L., Bonnin A., Crocker C., Kawauchi S., Murray R.C., Shou J. \& Wu H.H. 2002. Progenitor cells of the olfactory receptor neuron lineage. Microsc. Res. Tech. 58:176-188.
Carr V.M., Farbman A.I., Colleti L.M. \& Morgan J.I. 1991. Identification of a new non-neuronal cell type min rat olfactory epithelium. Neurosci. 45:433449.

Getchell T.V., Narla R.K., Little S., Hyde J.F. \& Getchell M.L. 2000. Horizontal basal cell proliferation in the olfactory epithelium of transforming growth factor-a transgenic mice. Cell Tissue Res. 299:185-192.

Goldstein B.J. \& Schowob J.E. 1996. Analysis of the global basal cell compartment in rat olfactory epithelium using GBC-1, a new monoclonal antibody against globose basal cells. J. Neurosci. 16:4005-4016.

Graziadei P.P.C. \& Graziadei G.A.M. 1979. Neurogenesis and neuron regeneration in the olfactory system of mammals: Morphological aspects of differentiation and structural organization of the olfactory sensory neurons. J. Neurocytol. 8:1-18.

Higuchi Y., Nakamura H., Kawasaki M. \& Takahashi S. 2005. The dynamics of precursor cells in the olfactory epithelium of juvenile and adult guinea pigs. Eur. Arch. Otorhinolaryngol. 262:64-68.

Hind J.P., Hind P.L. \& Mcnelly N.A. 1984. An autoradiographic study of the mouse olfactory epithelium: evidence for long-lived receptors. Anat. Res. 210:375-383.

Holcomb J.D., Mumm J.S. \& Calof A.L. 1995. Apoptosis in the neuronal lineage of the mouse olfactory epithelium: regulation in vivo and in vitro. Develop. Biol. 172:307-323.

Huard J.M.T., Yuongentob S.L., Goldstein B.J., Luskin M.B. \& Schwob J.E. 1998. Adult olfactory epithelium contains multipotent progenitors that give arise to neurons and no-neuronal cells. J. Comp. Neurol. 400:469-486.

Jin K., Mao X.O., Sun Y., Xie L. \& Greenberg D.A. 2002. Stem cell factor stimulates neurogenesis in vitro and in vivo. J. Clin. Invest. 110:311-319.

Kawauchi C.I., Breites C.E., Crocker C.E., Wu H.H., Bonnin R. \& Murray A.L. 2004. Molecular signals regulating proliferation of stem and progenitor cells in mouse olfactory epithelium. Develop. Neurosci. 26:166-180.

Kovacs T., Cairns N.J. \& Lantos P.L. 1999. Beta-amyloid deposition and neurofibrillary tangle formation in the olfactory bulb in ageing and Alzheimer's disease. Neuropathol. Appl. Neurobiol. 6:481-491.

Legrier M.E., Ducray A., Propper A., Chao M. \& Kastner A. 2001. Cell Cycle Regulation during Mouse Olfactory Neurogenesis. Cell Growth Differ. 12:591-601.

Levey M.S., Chikaraishi D.M. \& Kauer S. 1991. Characterization of potential precursor populations in the mouse olfactory epithelium using immunocytochemistry and autoradiography. J. Neurosci. 11:3556-3564.

Mackay-Sim A. \& Kittel P.W. 1990. On the life span of olfactory receptor neurons. Eur. J. Neurosci. 3:209-215.

Menco B.P. \& Jackson J.E. 1997. A banded topography in the developing rat's olfactory epithelial surface. J. Comp. Neurol. 388:293-306.

Nakamura H., Fujiwara M., Kawasaki M., Nonomura N. \& Takahashi S. 1998. Age-related changes in dividing cells of the olfactory epithelium of the maturing guinea pig. Eur. Arch. Otorhinolaryngol. 255:289-292.

Ohta Y. \& Ichimura K. 2000. Immunohistochemical localization of proliferating cells and epidermal growth factor receptors in mouse olfactory epithelium. J. Oto-Rhin-Laryngol. Rel. Special.1:20-25.

Pendleton N., Dixon G.R., Burnett H.E., Occleston N.L., Myskow M.W. \& Green J.A. 1993. Expression of proliferating cell nuclear antigen (PCNA) in dysplasia of the bronchial epithelium. J. Pathol. 170:169-172.

Roisen F.., Klueber K.M., Lu C.L., Hatcher L.M., Dozier A., Shields C.B., Maguire S. 2003. Adult human olfactory stem cells. Brain Res. 890:11-22.

Tsuji T., Sasaki K., Kimura Y., Yamada K., Mori M. \& Shinozaki F. 1992. Measurement of proliferating cell nuclear antigen (PCNA) and its clinical application in oral cancer. Int. J. Oral. Maxillofac. Surg. 21:369-372. 